As representações entremeadas no comércio de plantas medicinais em Goiânia/GO: uma reflexão geográfica Luiza Helena Barreira Machado

\title{
AS REPRESENTAÇÕES ENTREMEADAS NO COMÉRCIO DE PLANTAS MEDICINAIS EM GOIÂNIA/GO: UMA REFLEXÃO GEOGRÁFICA
}

\author{
Entering the Representations of the Trade in Medicinal Plants Goiânia/Go: \\ a Reflection Geographical
}

Luiza Helena Barreira Machado

Universidade Federal de Goiás, UFG, Brasil.

Goiania/GO - Brasil

looizabarreira@gmail.com

Artigo recebido para publicação em 08/09/2008 e aceito para publicação em 26/02/2009

RESUMO: $\quad$ O uso de ervas medicinais é corrente entre as diversas sociedades. Durante determinado tempo esse uso e os saberes diretamente ligados a ele foram desconsiderados e até menosprezados. Entretanto, esse é um costume que permaneceu e resistiu ao tempo e as hegemonias médicas e medicinais, pois a (r)existência dessas pessoas que comercializam plantas medicinais é algo comumente encontrado desde pequenas cidades a metrópoles no Brasil e no mundo. Mais do que uma comum e simples existência de mercadores de plantas medicinais, ela - esta existência - nos coloca questões sobre o porquê, como, onde, quais as conexões, o que assegura essa própria existência elou resistência. Desvelar a relação que essas pessoas estabelecem com o Cerrado - bioma que abrange grande parte do Brasil central , entender sua chegada e permanência na metrópole, suas raizes culturais nos leva a buscar como o Cerrado é percebido e representado por essas pessoas. Assim, propomos uma breve reflexão sobre as representações no estudo de plantas medicinais tendo como lócus Goiânia. Esses significados e relações estabelecidos demonstram que é possivel compreender esse universo e seus conhecimentos que atualmente invadem os universos urbano, acadêmico, científico e político. Para fazer essa análise buscamos uma abordagem cultural da Geografia identificando os raizeiros, seus conhecimentos, seus olhares e representações sobre o Cerrado.

Palavras-chaves: Plantas medicinais. Representações sociais. Redes sociais.

ABSTRACT: The use of herbs is common among the various societies. During this particular time and use the knowledge directly linked to it were ignored and even overlooked. However, this is a habit that remained and withstood the test of time and the medical hegemony, since existence of people trading medicinal plants is commonly found from small towns to cities in Brazil and worldwide. More than a common and simple existence of traders of medicinal plants, this existence raises questions about why, how, where, what the connections, which ensures the existence and / or resistance.To reveal the relationship this kind of people establish with the Cerrado - biome that covers much of central Brazil - to understand their arrival and stay in the city, its cultural roots leads us to look like the Cerrado is perceived and represented by them. Thus, we propose a brief reflection on the representations in the study of medicinal plants in Goiannia. These meanings and relationships established show that is possible to understand this universe and its knowledge that currently invading the worlds urban, academic, scientific and political. To do this analysis we seek a cultural geography of identifying the rooters(raizeiros), their 
As representações entremeadas no comércio de plantas medicinais em Goiânia/GO: uma reflexão geográfica Luiza Helena Barreira Machado

knowledge, their views and representations on the Cerrado.

Key words: Medicinal plants. Social representations. Social networks.

\section{Sobre estudos de plantas medicinais}

O uso de plantas com o objetivo de tratamento de moléstias nem sempre está associado à comprovação de sua eficácia. Isso acontece no caso do uso popular. Assim sua eficácia não é comprovada porque não há preocupações científicas nem comprobatórias nesse uso informal de plantas. Isso nos remete ao uso caseiro de plantas medicinais, aos saberes tradicionais, a medicina popular, isto é, aos usos feitos a partir de experiências e saberes passados de geração para geração, e em grande parte passados oralmente.

Para serem consideradas medicinais, dentro da ciência moderna, as plantas têm que apresentar substâncias de ação farmacológica, que ajam direta ou indiretamente como medicamento. Mas para ter esse reconhecimento é necessário que sua autenticidade, integridade e pureza sejam comprovadas, como enfatiza Tourinho (2000, p. 36). Essas três etapas se referem respectivamente à identificação da espécie botânica, à identificação de substâncias químicas e ao controle microbiológico que possibilita a identificação de algum possível tipo de contaminação. Os raizeiros não têm essa preocupação técnica e científica de identificação das espécies, substâncias químicas e nem de contaminação. Seus saberes não têm os mesmos métodos e instrumentos que as ciências, eles se baseiam na observação e nas características exteriores das plantas, ou seja, na prática do dia-a-dia, no saber passado de pai para filho.

Mas aos poucos a ciência moderna tem se voltado aos saberes populares na busca de sua comprovação para que possam ser utilizados e comercializados de maneira segura. Assim, tratar atualmente de plantas medicinais aproxima cotidiano e ciência, visto que o uso de plantas, chás para curar mal-estar, dores de cabeça, cólicas está presente no dia-a-dia dos homens e mulheres ao longo de séculos. No que diz respeito ao reconhecimento governamental, atualmente o Governo Federal trabalha para implementar a Política Nacional de Plantas Medicinais e Fitoterápicos (PNPMF). Aprovada em 2006, esta política tem caráter interministerial e entre seus objetivos podem ser encontrados, o incentivo à produção de plantas medicinais através da agricultura familiar, a introdução do uso de plantas e fitoterápicos no Sistema Único de Saúde (SUS), o investimento em pesquisas, entre outros.

Diversas ciências têm se debruçado sobre o estudo das plantas medicinais. A Biologia, a Química, a Medicina, a Farmácia, entre outras, têm procurado descobrir o potencial de atuação de cada planta; a melhor forma de uso, a quantidade exata, os efeitos colaterais, as reações diversas e adversas, as interações possíveis, a eficácia e como sintetizar tais remédios para a produção em larga escala. Outras ciências como a Agronomia tem pesquisado maneiras específicas de cultivos, de forma a possibilitar melhor e maior produção de determinadas substâncias químicas; a Antropologia, averiguado o uso e inserção dessas plantas em cada cultura; a História tem registrado a evolução de usos diversos e de pesquisas de plantas medicinais.

A historiadora Fernandes (2004), em seu livro Plantas medicinais memória da ciência no Brasil, apresenta uma contribuição significativa ao registrar a memória da ciência. Faz ao mesmo tempo um levantamento da produção científica desde o I Simpósio de Plantas Medicinais do Brasil, que ocorreu em São Paulo, em 1967 até o XVII Simpósio, em Cuiabá, 2002.

Esta autora constata que no primeiro simpósio foram publicados 104 trabalhos de diferentes 
instituições de todo o Brasil. Nesse momento as principais áreas de pesquisa eram a medicina, a botânica, a farmacologia, a química; representadas principalmente por universidades - como a USP, UFRJ, Unesp, UFC, UFPR, UFMG, Unifesp, PUCSP, USP-Riberão Preto, etc.; laboratórios como Lilly do Brasil, Hoechst do Brasil, Estrela, Procienx, etc.; institutos de pesquisas Fio Cruz, Butantan e Lorenzini, e órgãos governamentais como o CNPQ e Fapesp. Dentre os 104 trabalhos destacaram-se 22 trabalhos não vinculados a nenhuma instituição.

Já no XVII Simpósio, ocorrido em 2002, o total de trabalhos foi de 870 , distribuídos entre as seguintes áreas de pesquisa: agronomia (85), botânica (115), controle de qualidade (46), farmacologia toxicologia (9), farmacognosia (68), farmacotécnica (414), química (133). Nesse mesmo simpósio participaram 102 diferentes instituições dentre universidades, institutos de pesquisa e órgãos públicos. Esse levantamento de Fernandes demonstra as principais áreas que desenvolvem pesquisas, e seu crescimento no Brasil no período de 1967 a 2002. Todos estes dados levantados revelam a situação da pesquisa sobre plantas medicinais no país, uma média de produção de cada ciência e seu aumento.

Na Geografia existe um pequeno número de pesquisadores interessados nessa temática em específico. Há também a dificuldade de divulgação e comunicação das pesquisas e pesquisadores. As pesquisas, por vezes, não exploram o lado subjetivo e/ou a cultura envolvida nos usos. Muitas vezes o foco das pesquisas é apenas o uso da planta. No entanto, com a evolução e ampliação da Geografia novas teorias, metodologias e campos de pesquisas vão surgindo. Diante disso, temas como este são entendidos como "novos" e, por vezes, não são compreendidos.

Além de resultado da expansão da geografia, esses "novos" temas são produtos e produtores de aproximação entre campos diferentes da ciência. A complementaridade das ciências gera uma aproximação da Geografia com outras diversas ciências em diversos estudos. Da mesma forma, a aproximação de pesquisadores de diversas áreas influencia o estudo de novos temas e discussões para outras ciências.

O nosso artigo, de natureza geográfica, busca a compreensão do espaço, entendendo as redes estabelecidas no processo de comercialização de plantas medicinais em Goiânia. O que se propõe é compreender aspectos reticulares como também as representações sobre plantas medicinais e, consequentemente, sobre natureza, que os raizeiros têm. São essas representações que dão sentido a existência das redes, e as redes gerando a mudança espacial, que por sua vez influenciarão as representações.

Utilizamos uma entrevista semi-estruturada, a qual continha temas relacionados aos pontos comerciais, redes, representações, saberes, suas origens e transmissão. Primeiro foram localizados e depois selecionados os raizeiros para a realização das entrevistas. A seguir estão apresentados os resultados relativos às representações das entrevistas realizadas com raizeiros do Setor Central.

\section{As representações}

Para explicar determinadas ações e usos no/ do espaço, foi nos indispensável chegar ao conhecimento do que move as pessoas às ações e aos usos, quais são suas crenças, símbolos, ritos e saberes e como agem a partir deles. Assim, na busca da compreensão da realidade das pessoas que comercializam plantas medicinais em Goiânia procuramos explorar o sentido que leva ao comércio dessas plantas, ou seja, ao estabelecimento das redes comerciais dessas ervas.

Pautados nesse objetivo, de compreender porque as pessoas usam plantas medicinais, consequentemente incentivando o estabelecimento $\mathrm{e}$ crescimento do comércio das mesmas, que optamos pela categoria representações. Como clareia Almeida

[...] o estudo das representações espaciais centrase sobre as modalidades de apreensão do mundo e do status do real, isto é, o problema da adequação 
entre a realidade, o que nós percebemos e nossos discursos sobre a realidade. É através de um conhecimento das representações das pessoas que é possível captar toda a riqueza de valores que dão sentido aos lugares de vida dos homens e das mulheres; pelas representações também é possível entender a maneira pela qual as pessoas modelam as paisagens e nelas afirmam suas convicções e suas esperanças.(ALMEIDA, 2003a, p.71)

Almeida toca no ponto que nos interessa nessa pesquisa. Ela é direta ao afirmar que as representações espaciais estão no cerne da maneira que os homens apreendem o mundo. Isso significa que cada pessoa com o seu modo de compreender o mundo gera também suas próprias representações. As representações vão funcionar como a síntese da adequação da realidade, do que nós percebemos e dos nossos discursos sobre a realidade.

A autora ainda afirma a importância do estudo das representações ao enfatizar que é a partir do conhecimento das representações que será possível compreender a riqueza dos valores que dão sentido aos lugares, entender a modelagem das paisagens e as convicções e esperanças afirmadas nelas. Assim, é importante conhecer as representações para captar essa riqueza, seus detalhes, especificidades, símbolos para compreender a cultura que gera esse significado às ações e modelagens da paisagem.

Com o estudo das representações, chega-se, também, ao conhecimento das culturas, pois elas são diferentes, bem como, os lugares, os significados e as ações e reações de cada povo, de cada ser humano. No mesmo sentido que Almeida, o questionamento feito por Claval vem contribuir sobre a importância de considerar as representações ao procurar compreender o espaço:

Por que os indivíduos e os grupos não vivem os lugares do mesmo modo, não os percebem da mesma maneira, não recortam o real segundo as mesmas perspectivas e em função dos mesmos critérios, não descobrem neles as mesmas vantagens e os mesmos riscos, não associam a eles os mesmos sonhos e as mesmas aspirações, não investem neles os mesmos sentimentos e a mesma afetividade? (CLAVAL, 2001, p. 40)

Quando este autor faz este questionamento ele nos remete tanto ao individual quanto ao coletivo, e a questão das especificidades de cada ser humano como de cada grupo. Essas especificidades e singularidades em seus pensares, ações e reações, construções, relações e inter-relações são construídas a partir da subjetividade de cada grupo. E as diferentes relações mediadas pela subjetividade individual e coletiva geram valores e usos diversos. O uso das palantas medicinais tem um campo subjetivo, pois está diretamente ligado aos valores, às crenças, à fé no poder curativo.

O campo da subjetividade é, sem dúvida, o que vai demonstrar as percepções individuais e representações sociais. E registrar o que é observado, o que é ignorado, o que é falado e do que se foge numa conversa, capturar os gostos e desgostos, as relações de respeito e objetos valorizados, as ações e reações, as canções que cantam a vida, o trabalho, a dor, a dificuldade é caminho para se chegar a compreensão dessa subjetividade. Juntamente a essas observações e registros, a compreensão dos sistemas de comunicação, valoração, construção de vida de cada grupo social e as singularidades e especificidades de seus indivíduos, sua produção e realidades, é que a análise se torna completa.

Nessa mesma acepção de compreensão de diferentes realidades, nos interessou desvelar as representações e os significados das plantas medicinais e da natureza que perpassam na atividade comercial dessas plantas. E a partir das representações dos raizeiros compreender o que incentiva ou motiva as pessoas a dedicarem-se a venda de plantas.

Pesquisas sobre representações sociais têm sido desenvolvidas por várias áreas do conhecimento, dentre elas pode-se destacar a Antropologia, a Sociologia, a Sociolinguística, a Geografia e outras. Mas, tal estudo tem sua origem e base na Psicologia, e sua ideia embrionária vem da teoria de Durkeim 
sobre representações coletivas. A partir desse conceito de representações coletivas, Serge Moscovici desenvolve na Psicologia o conceito de representações sociais, o qual fundamenta este estudo.

Moscovici, há mais de quarenta anos introduziu o conceito de representações sociais na Psicologia Social contemporânea. A Teoria das Representações Sociais revolucionou a Psicologia e as ciências sociais, como a Sociologia, Antropologia e a Comunicação. Este autor, em seu livro "Representações Sociais: investigações em Psicologia Social”, esclarece que, essa é a teoria das representações sociais, pois, "é o fato de esta teoria tender mais e mais na direção de se tornar uma teoria geral dos fenômenos sociais e uma teoria específica dos fenômenos psíquicos" (MOSCOVICI, 2003, p.173, grifos nossos).

Ela, a teoria das representações, então, é entendida como teoria geral no sentido em que o ajuntamento de indivíduos é reconhecido como sociedade e para isso devem existir representações ou valores que lhes deem sentido e que garantam sua existência em comum. É teoria específica dos fenômenos psíquicos na medida em que isso tudo se dá a partir dos indivíduos, das opiniões.

As representações sociais, como afirma Jodelet, discípula de Moscovici, "são produto e processo de uma atividade de apropriação da realidade exterior ao pensamento e de elaboração psicológica e social dessa realidade" (2001, p. 22). Sendo assim as representações são influenciadas por diversas estruturas sociais, redes, outros indivíduos etc.

Estudos que buscam essa compreensão têm sido desenvolvidos no Brasil. Segundo a mesma autora, há mais de vinte anos o estudo sobre representações sociais vem se desenvolvendo no país. Ela destaca que a produção no campo das representações sociais "foi implementada, sobretudo e com uma multiplicidade particular, nesses três domínios (da saúde, da educação e do trabalho), tanto por razões históricas, quanto pela adequação entre suas problemáticas próprias e os recursos de análise oferecidos pela teoria" (JODELET, 2004 p. 8).
Qual seria então para a Geografia sua utilidade? Conforme Almeida (2003), por sua singularidade de ter o espaço como objeto

O espaço, além de ser produto das atividades humanas, tem múltiplas valorizações e caracterizase por atributos funcionais, estruturais e afetivos. Espaço pode ser então, considerado como o lugar onde os homens e mulheres, ideologicamente diferentes, procuram impor suas representações, suas práticas e seus interesses. Cada espaço, tornando-se social, está possuído de símbolos e afetividades atribuídos pelas pessoas. (ALMEIDA, 2003a, p. 71)

As representações são importantes mesmo no sentido de compreendermos as coisas, os processos, os sistemas a partir de representações do outro, pois na opinião de outro autor, "é em contraste - ou às vezes por analogia - com as representações de outra sociedade que apreendemos melhor os caracteres e o funcionamento dessas configurações que denominamos de representações sociais" (HERZLICH , 2005 p.63).

Kozel (2002, p.223) trabalha com a ideia de que a "representação como conhecimento que permite ao indivíduo se apropriar do mundo exterior, acompanhado de palavras e ideias comunicáveis." Outra questão, relativa às representações é levantada por essa mesma autora (2002), quando afirma que elas são produto e produtoras do espaço e das próprias representações. E ao fundamentar teóricoconceitualmente o uso das representações em geografia destaca a existência de três concepções: a realista (embasa o real), a idealista (dá suporte teórico ao imaginário) e a sociocultural (que perpassa as duas concepções, proporcionando a análise da teia de relações estabelecidas entre a sociedade e o espaço geográfico).

Na primeira concepção, a realista, "as representações são, portanto, produtos da percepção, integradas pela dimensão simbólica. Não considera as interferências da afetividade e do meio social, e prioriza as dimensões biológicas do desenvolvimento humano" (KOZEL, 2002 p. 224). Essa concepção se 
baseia nas correntes filosóficas positivistas e neopositivistas e tem a neutralidade como suporte de uma visão de mundo que postula que o objeto existe independente do pensamento. Aqui o objeto aparece como o centro.

Essa concepção, no nosso entendimento, é caduca no sentido, principalmente, da neutralidade. Como se o conhecimento estivesse pronto e acabado no objeto e que o sujeito em nada interfere nele.

A segunda concepção compreende o real como um produto da mente, do pensamento, da consciência. Assim, entendendo a representação como uma metáfora do conhecimento. Ainda é Kozel quem explicita que nessa concepção a

[...] realidade é captada pelo conhecimento sensível, imaginário e abstrato, proporcionando a construção e reconstrução da realidade, explicando-se por meio das representações, que num primeiro momento acontecem como 'síntese cognitiva', passando pela memória/consciência em direção à seletividade, apontando para a lente que se usa para ver e conceber o mundo e as coisas pertinentes a ele. (KOZEL, 2002, p. 225, grifo nosso)

Nessa abordagem o sujeito é o centro. E o importante é a construção de conhecimento através dos sentidos. São entendidos não apenas como objetos dados. "As coisas não podem ser conhecidas por si mesmas, mas pelas representações que fazemos delas; as leis são produtos do entendimento e não ensinamentos provenientes da natureza" (KOZEL, 2002 p. 226).

Completamente oposta à primeira concepção, a segunda parte do princípio de que o que é importante são as interpretações humanas, suas construções e significações. Não é útil também essa visão extremada de análise, pois, apenas as opiniões, representações e interpretações humanas isoladas de um contexto perdem seus sentidos.

Diante disso, observam-se duas concepções opostas. A primeira que valoriza o objeto e a segunda que valoriza o sujeito. Mas além dessas duas concepções muitas outras surgem variando entre os extremos delas. Considerando a relação epistemológica sujeito-objeto a terceira concepção, a sociocultural, postula um sujeito construtor do mundo e de si mesmo. É nessa vertente, associada à teoria social, que a fundamentação da autora resulta.

Comungamos das ideias apresentadas por Kozel demonstrando que a realidade não existe apenas de maneira objetiva sem a necessidade da percepção humana; nem é da pura construção do conhecimento pautada somente nos sentidos, no real como resultado da construção do pensamento. Assim, no entendimento sociocultural "as representações sociais estabelecem uma síntese entre os fenômenos cognitivos, afetivos e sociais, que na realidade estão completamente interligados, permitindo a incorporação de análises ideológicas, dos saberes populares e do senso comum", (2002, p.227) encontramos eco no que afirmamos.

$\mathrm{Na}$ mesma direção de entendimento de representações, Coutinho complementa afirmando que

A história das representações sociais insere-se na inter-relação entre atores sociais, o fenômeno e o contexto que os rodeia. Elas são constituídas por processos sociocognitivos e têm implicações na vida cotidiana, influenciando a comunicação e os comportamentos. Desta forma a representação pode ser considerada como um sistema de interpretações da realidade, organizando as relações dos indivíduos com o mundo e orientando suas condutas e comportamentos no meio social. (COUTINHO et all, 2004, p. 469 e 470, grifos nossos)

Destarte, reafirma-se a importância do uso de representações sociais para compreender a organização das relações entre indivíduos que comercializam e que usam plantas medicinais, suas condutas e comportamentos a partir de suas representações de realidade, do mundo. Como pode ser observado na Fig. 1, esse processo de formação 
das representações sociais e suas interferências ou implicações na vida cotidiana é que propomos compreender como se dá a comunicação e o comportamento dos raizeiros de Goiânia. Ela será feita pela leitura da relação dos atores sociais, dos fenômenos e do contexto que os rodeia.



Figura 1. Esquema explicativo do processo de formação e interferência das Representações Sociais Organizado por: Machado, L.H.B. com base em Coutinho et all, 2004

Claval afirma que: "A partir da representação cria-se uma abordagem mais social; a atenção dada às ferramentas e às práticas é menor; e as representações, ao apontar o papel central das culturas levam a uma visão onde os grupos aparecem como essenciais."(2007, p. 10). A proposta de entendê-los como essenciais leva à busca da compreensão de suas representações formadas da relação dos atores sociais, do fenômeno e do contexto.

O fato de comercializarem essas plantas em vilas e grandes cidades, mesmo com o objetivo primeiro de se sustentar, implica diretamente na difusão de determinada prática cultural, expressa pelo uso e conhecimento das aplicações de plantas, em especial as de potencial medicinal, e a propagação desse conhecimento. Assim, o foco é o estudo da cultura dos raizeiros, pois, como esclarece Claval,

a cultura é o conjunto de representações sobre as quais repousa a transmissão, de uma geração a outra ou entre parceiros da mesma idade, das sensibilidades, idéias e normas. Ela inclui a imagem do meio ambiente próximo e os conhecimentos, práticas e ferramentas que permitem tirar partido dele. Ela comporta um arsenal de métodos para se orientar. (CLAVAL, 2002, p. 141 e 142, grifos nossos)

Em conformidade às palavras de Claval, e somando ao que foi dito, a utilização da categoria representação possibilita compreender a cultura dos raizeiros pelo entendimento das representações, das imagens de meio ambiente próximo, dos conhecimentos, das práticas e das ferramentas das pessoas que utilizam plantas medicinais.

\section{Sobre os raizeiros de Goiânia}

Neste estudo definiu-se como raizeiro qualquer pessoa que tenha conhecimentos e/ou faça uso indicativo de plantas medicinais. Também, passase a entender que a pessoa que comercializa as plantas é um raizeiro mercador.

O alvo da pesquisa foram os raizeiros mercadores, distribuídos por toda a cidade de Goiânia, cidade onde habitam aproximadamente 1.200.000 pessoas, em mais de 200 bairros. Esses raizeiros podem ser encontrados em feiras, mercados, lojas e até mesmo em bancas ambulantes. No Setor Central de Goiânia, encontra-se número significante de raizeiros, totalizados 17, dado obtido em trabalho investigatório. As principais concentrações destes mercadores estão no Mercado Central, no Mercado Aberto, aos arredores do cruzamento das avenidas Goiás e Paranaíba e na Feira Hippie. Já no Setor Campinas a concentração ocorre nas Avenidas Anhanguera e 24 de outubro e suas imediações, totalizando 16 raizeiros. Em sua maioria estão em lojas, mas são encontrados feirantes, ambulantes e no Mercado de Campinas. As feiras-livres semanais, em toda Goiânia, também apresentam presença de raizeiros. E ainda constatou-se mais pontos comerciais em demais bairros. Averiguou-se, então, 
As representações entremeadas no comércio de plantas medicinais em Goiânia/GO: uma reflexão geográfica Luiza Helena Barreira Machado

que as duas áreas de maior concentração em Goiânia são o Setor Central e o Setor Campinas, com 33 raizeiros localizados.
Na Fig. 2 estão localizadas as 27 feiras, nas quais se observa a presença de raizeiros, 16 lojas, 1 banca e 7 mercados que contém vários raizeiros.



Figura 2. Mapa de localização dos estabelecimentos que contêm raizeiros em Goiânia - GO

Nos dois tópicos a seguir estão destacadas a localização e as falas de raizeiros de Goiânia localizados no Setor Central, com os quais foram realizadas entrevistas com objetivo de "capturar", através do exercício de seu ofício, os saberes e os olhares, isto é, as representações que estes têm do cerrado.

\section{Localização dos raizeiros no Setor Central}

Até por volta de 1970, o Setor Central era considerado bairro habitacional das classes médiaalta e alta da cidade, a partir dessa época muda sua configuração. As classes média-alta e alta se transferem para outros setores como o Marista, Bueno e Oeste e atualmente têm se transferido para os condomínios de luxo em áreas periféricas. Essa mudança de funcionalidade ocorre com a desvalorização habitacional e simultânea valorização comercial. Assim, o comércio no setor cresce e ganha força se tornando atualmente seu maior atrativo.

A caracterização deste setor reflete seu aspecto comercial - que abriga grande número de empresas e lojas, como lojas de calçados, de roupas, de eletrodomésticos e eletroeletrônicos além do grande número de livrarias e papelarias; e o grande fluxo de pedestres que circulam por ele-grande parte 
da população é obrigada a transitar pelo Setor Central seja como objetivo, conexão de transporte coletivo ou passagem, pois existem linhas de transporte urbano que levam passageiros das periferias para o centro onde parte trabalha - e outras linhas que levam do centro para outros bairros. Existe também a linha de ônibus Eixo Anhanguera, que como o nome diz faz seu trajeto pela Avenida Anhanguera, que atravessa a cidade de leste a oeste. Atualmente, possui a menor tarifa do sistema metropolitano de transporte de Goiânia custando apenas R $\$ 1,00$ (um real), enquanto a passagem das demais linhas custa $\mathrm{R} \$ 2,00$ (dois reais). Essa enorme diferença do preço de passagens faz muitas pessoas andarem grandes trajetos - de 2 a 4 quilômetros - a pé até uma parada do Eixo Anhanguera, para diminuírem o gasto com transporte. Apesar do grande percurso dessa linha, que possibilita a ligação direta entre as regiões leste/oeste da cidade, assim parte de seus usuários não têm necessidade de descer no centro, mas outra parte de seus usuários passam e/ou descem no centro.

Esse grande fluxo de pessoas, não se resume apenas aos moradores da cidade de Goiânia e trabalhadores que habitam na região metropolitana, mas também de outras cidades do Estado e de todo o país. Goiânia é referência nacional na área médica e odontológica, e comercial - com destaque para a grande quantidade de feiras, como o Mercado Aberto de Goiânia e a Feira Hippie, ambas no centro e de confecções.

A partir dessas características do centro urbano este torna-se um ótimo lugar para se instalarem os raizeiros mercadores - pessoas que se sustentam desta atividade, assim podem comercializar seus produtos, pois o centro da cidade se estabelece como centralidade importantíssima na cidade. Essas características não são exclusivas do Setor Central, vão se repetir no Setor Campinas também, e elas não impedem que outros setores abriguem raizeiros. Toda essa atração e dinâmica comercial dessa centralidade atraem os raizeiros em número significante distribuídos em lojas, feiras, mercados e ambulantes.

Neste artigo optamos por destacar as características do Setor Central como pode ser observado a seguir: o Mercado Central, localizado entre a Rua 3 e a Avenida Anhanguera no Centro abriga um comércio variado desde bancas que vendem artigos para cama, mesa e banho, utensílios variados, vestuário e calçados, até mesmo serviços de assistência técnica, alimentação, souvenir's e raízes. Nesse mercado localizam-se oito bancas de raízes, onde encontram-se cinco raizeiras e três raizeiros.

Dentre as principais avenidas da cidade está a Avenida Goiás, que começa na Praça Cívica e atravessa o Setor Central no sentido Sul-Norte. No encontro das Avenidas Paranaíba e Goiás localiza-se um raizeiro em uma pequena banca de ferro, que sempre fica ali: R-2. Natural da Bahia, este raizeiro, trabalha com plantas medicinais há 28 anos e está neste ponto há 12 anos.

Logo, em frente, na Paranaíba, encontra-se o Mercado Aberto de Goiânia, dividido em duas partes: uma ao lado leste da Avenida Goiás, onde encontramse três raizeiros, e outra parte, ao lado oeste da mesma avenida, e nela um raizeiro foi encontrado. Ainda na Paranaíba localizamos outro mercador na esquina com a Rua 70.

A Feira Hippie acontece aos domingos pela manhã. Sua localização, ao lado da Rodoviária, facilita para muitos clientes de outras cidades chegarem à feira, aumentando o número de compradores de fora da cidade. Dos raizeiros encontrados na Feira Hippie, dois se caracterizam por bancas montadas em carrinhos e uma raizeira pela barraquinha de feira. Todos os três possuem barracas fixas e cadastradas no Mercado Aberto de Goiânia.

Cada banca traduz o universo em que vive o raizeiro, a sua história, sua convivência e conhecimento sobre a natureza. Pela disposição dos produtos, das receitas e dos conselhos, muito se pode aprender sobre esses singulares e semelhantes universos, como o respeito pela natureza, a persistência e a fé, que sempre acompanham as receitas do R-1: "Tem que ter fé também, que a fé ajuda na recuperação". 
As representações entremeadas no comércio de plantas medicinais em Goiânia/GO: uma reflexão geográfica Luiza Helena Barreira Machado

\section{Alguns olhares e representações sobre o Cerrado}

De acordo com os seus conhecimentos sobre o Cerrado, é possível identificar raizeiros que conseguem descrever o Cerrado, como a raizeira $\mathrm{R}$ 18 que diz, é aquele mato rasteiro que olha até longe e tem algumas árvores (28/10/2005).

Esta fala consegue remontar uma paisagem visual típica do Cerrado, lembrando as fisionomias de Campo limpo e Campo Sujo. Por esta conseguese capturar aspectos peculiares do bioma. Isso evidencia que alguns raizeiros, como R-18, possivelmente viveram em zonas rurais pelo menos durante um período de sua vida. E esta vivência é expressa ao responder a entrevista afirmando que já passou parte da vida em áreas de Cerrado. Também, é ratificado em suas outras colocações como a supracitada. A forma como ela descreve, o cuidado e a segurança são de quem fala com propriedade.

Mas nem todos conseguem dizer o que é o Cerrado exatamente, como pode ser notado nas falas a seguir. Fazem algumas confusões com outros biomas, outros empregam definições que são um tanto quanto vagas ou mesmo simplistas, como os exemplos a seguir:

$$
\begin{aligned}
& \text { “É uma mata (R-19, } 26 \text { anos - 04/11/2005)". } \\
& \text { "É.. cinqüenta por cento das plantas é cerrado } \\
& \text { (R-1, } 50 \text { anos - 05/11/2005)". } \\
& \text { "É tudo (R-3, } 52 \text { anos - 05/11/2005)". } \\
& \text { "Lugar de campo onde tem remédio" (R-4, } 54 \\
& \text { anos - 05/11/2005). }
\end{aligned}
$$

"Pra mim? Nunca pensei. Ë um lugar bom pra se viver. Eu gosto dessas coisas, rio, mato" (R-26, 25 anos - 20/11/2005).

"Matagal" (R-25, 29 anos - 20/11/2005).

"Importante é o campo" (R-23, 30 anos - 04/11) 2005).
"Para a plantá, e para colher" (R-15, 39 anos 04/11/2005).

"É aquele, o campo, onde... cerrado, deserto" ( $R$ 16, 04/11/2005).

"Aqui é Cerrado, na Bahia gramas. Goiás não tem madeira de lei. Só madeira fraca" (R-2, 62 anos -04/11/2005).

"Tá mudando precisa ser preservado" ( $R-24,32$ anos -04/11/2005).

"Vegetação rasteira, campo. Terra fértil" ( $R$-20, 50 anos - 04/11/2005).

"É um terreno fraco, que chama caatinga na Bahia. Um tipo de cultura. Mata rasteira" (R-17, 77 anos - 28/10/2005).

"Uma coisa interessante onde tem ervas" (R-29, 04/11/2005).

"Natureza mais completa de plantas" (R-22, 55 anos - 04/11/2005).

"Cada especialidade é as plantas. Mata, Campo" (R-27, 10/10/2005).

Alguns conseguem remontar uma paisagem natural. Outros, nem tanto, e alguns não sabem ou como o que disse R-26: "nunca pensei". Mesmo a maioria não conseguindo dizer exatamente o que é o Cerrado nota-se a presença de outros temas nas falas. Como, por exemplo, "a importância", "é local de plantar e colher", "necessita ser preservado" e "é o local onde se encontram plantas medicinais".

Quando o assunto é sobre o conhecimento, lembram com muita facilidade e empolgação como foi adquirido sobre as plantas e seus benefícios, foi passado no dia-a-dia, com a vivência tida com as pessoas mais experientes sejam pais, mães, tios, tias, sogras e sogros. Relatam que este conhecimento "é coisa de família, passado de geração para geração", como enfatizou o R-2. Porém, alguns como o R-19,

Sociedade \& Natureza, Uberlândia, 21 (1): 159-172, ABR. 2009 
R-24 e R-20 nascidos na cidade, em Goiânia, tiveram uma iniciativa diferente. Eles que se interessaram e buscaram o conhecimento em informações, livros, Internet.

Nas respostas sobre animais pertencentes a este bioma aparecem citados o Tatu Peba, Tatu Bola, Ema, Seriema, Veado Mateiro, Caititu, Porco-domato, Macaco, Cavalo, Cachorro, Nambu, Tamanduá, Paca, Cateto, Raposa, Codorna, Perdiz, Cobra, Capivara, Onça, Lagartixa, Calango, Tiú, Coelho, Jacaré e Anta. Percebe-se não há uma distinção de espécies relacionada ao bioma, mas demonstram que conhecem alguns dos animais do Cerrado, e outros ainda, que são domesticados.

O Cerrado era diferente há algum tempo atrás sim, na opinião de $82 \%$ dos entrevistados. O restante não respondeu ou não soube responder. As respostas são muito semelhantes, e duas que representam bem destacam que:

"Ele está é acabando, com arado, plantio e barracão" (R-18 - 28/10/2005)

"Tá acabando". (R-1, 54 anos - 05/11/2005)".

A primeira é uma resposta que contem um conhecimento empírico da destruição do Cerrado e o segundo demonstra a obtenção da informação vaga e simplista não explica como e por que está acabando. Esta resposta não evidencia conhecimento de causa. Estes tipos de respotas, mais uma vez diferenciam a vivência e, como dito anteriormente, o conhecimento empírico.

Sobre o uso do Cerrado os raizeiros foram unânimes em dizer que deve ser protegido. Pode e deve haver plantações e gado, mas também deve ter parte preservada, de onde eles possam continuar contando com a possibilidade de retirar plantas para o seu sustento. Observe a seguir algumas falas:

"Deve ser usado pra tudo [gado, soja e mato]. Eles precisam plantar e a gente colher". (R-25, 29 anos - 20/11/2005).
"Tem que ter a consciência [para usar], mas tem que deixar umas áreas". (R-22, 55 anos - 04/11/ 2005).

"Desse jeito vai ser destruido, acabar. Tem que preservar”. (R-20, 50 anos -04/11/2005).

“Não mexer. Era o certo, mas...". (R-15, 39 anos -04/11/2005).

Quando o assunto foi o fogo houve algumas divergências. Existem aqueles raizeiros afirmando que nunca se deve colocar fogo no Cerrado. E outros que afirmam que até pode, para poder plantar e fazer pasto. Mesmo na academia esta é uma discussão muito polêmica. O que já é cientificamente provado é que algumas espécies têm a dormência das sementes quebradas pelo fogo.

Sobre as histórias relacionadas ao cerrado muitos deles não fazem referência ou não se lembram. Um personagem que apareceu em três entrevistas foi o "Pai do mato". Que segundo eles é um homem que vive no mato para proteger a mata. Descontraídos, os raizeiros se esforçaram para demonstrar o conhecimento sobre o cerrado, com lembranças de alguma música relacionada ao cerrado. Apareceram as seguintes:

"Já ouvi aquela música das frutas, de cajuzinho. E piadas do Nilton Pinto e Tom Carvalho" (R-1, 50 anos - 05/11/2005).

"Uma música que eu cantava quando morava lá em Brasília: Um pé de pequi, de ipê amarelo. Cuidar do cerrado é tudo o que eu quero" (R-26, 25 anos - 20/11/2005).

Além dos saberes e representações relacionados ao Cerrado este estudo ainda revelou que em Goiânia as redes comerciais que se formam sofrem grande influência das relações familiares. Dessa forma, fica confirmado que a família é o elo de transmissão de saberes e representações sociais, e também fica desvelado que estes saberes e representações, por sua vez, geram o crescimento da rede comercial goianiense. 
Observe que em vermelho aparecem os 4 raizeiros irmãos (R-1, R-2, R-3 e R-4), em roxo estão pessoas que trabalharam com R-1 e depois abriram seus próprios estabelecimentos. E, por fim, em azul está a ampliação de estabelecimentos de R-5 ("Rei das Raízes”) e R-13 (“A raizeira”). Como esta rede se baseia na solidariedade de saberes e incentivos de inserção no comércio de plantas medicinais de Goiânia esta rede se classifica também como uma Rede Christalleriana.



Figura 03. Rede Christalleriana de Ervanarias em Goiânia/GO - 2008

Fonte: Elaborado por Machado, L.H.B. com base nas entrevistas, 2008.

Diante das declarações apresentadas e outras mais, ou mesmo lendo as entrevistas realizadas, poderíamos arbitrariamente dizer que os raizeiros não entendem muita coisa sobre o Cerrado. E estaríamos desqualificando a cultura e o conhecimento dessas pessoas e agindo de forma preconceituosa e superficial. Mais do que saber conceitos e nomes científicos, estas pessoas entendem o Cerrado pela vivência e convivência, como a Natureza que os sustenta, como um lugar de lembrança de determinada época da vida, lugar de saudades. Podem não conhecer nomes científicos e nomes de estratificações, mas conhecem o que pode curar e matar. Respeitam o poder que a Natureza lhes oferece. Entendem o mato, o matagal, a partir de suas vivências, pois, o que é o mato, o Cerrado, a Amazônia ou a Caatinga senão a natureza?! 
Não é a falta de aprofundamento ou de conhecimento conceitual ou classificatório sobre o Cerrado que mede os conhecimentos desses raizeiros. Este conhecimento é tão importante quanto o conhecimento desenvolvido pelas Ciências. Rigonato e Almeida (2004, p. 48) fazem a seguinte consideração sobre o conhecimento tradicional:

[...] o conhecimento popular das populações tradicionais é um instrumento indispensável para a preservação da cultura, da persistência de modos de vidas tradicionais e da biodiversidade do Cerrado. E também, auxilia os estudos científicos que buscam conhecer, identificar, catalogar a espacialização das espécies e as potencialidades, medicinais, artesanais e frutíferas dos estratos fitofisionômicos do Cerrado.

Assim, procuramos neste estudo fazer uma explicação de uma realidade tendo o embasamento dos autores supracitados. É só pelos conhecimentos populares, dos raizeiros, que sua cultura e modos de relacionamentos com o Bioma Cerrado vão continuar a existir. Não podemos cair no erro de desconsiderar seus conhecimentos como de pouca contribuição para o desenvolvimento da ciência. E mais, cabe à ciência, que procura apreender seus tipos de relacionamentos e usos do Cerrado, entender o papel que o raizeiro tem em até auxiliar na conservação do Cerrado e na descoberta do uso de plantas posteriormente.

O que se constata neste estudo é que a existência de raizeiros comercializando plantas medicinais revela a demanda existente na sociedade goianiense. Demonstra que essa demanda reorganiza o espaço da cidade a medida que se estabelece o comércio. Isso tudo regido pelas representações e saberes transmitidos pelos elos familiares e de amizade.

\section{Referências}

ALMEIDA, Maria Geralda de. Em busca do poético do sertão. In: GEOGRAFIA: leituras culturais. ALMEIDA, M. G., RATTS, A. J. P. Goiânia: Alternativa, 2003a. 284 p., il. Inclui bibliografia. ISBN 8588253194 (broch.).
ALMEIDA, Maria Geralda de. Cultura ecológica e biodiversidade. Mercator, Fortaleza, ano 2, n.3, p. 7182, jan./jul. 2003.

CLAVAL, Paul. O papel da nova geografia cultural na compreensão da ação humana. In: CORRÊA, Roberto Lobato; ROSENDAHL, Zeny (Org.) Matrizes da Geografia Cultural. Rio de Janeiro, RJ: EdUERJ, 2001.

A reinvenção da natureza. Espaço e cultura, Rio de Janeiro, n.3, p. 41 - 53, jan./dez. 2004.

. "A volta do cultural na geografia". Revista Mercator, ano 01, número 01, p.19-28, 2002.

. Apresentação. In: KOZEL, S.; SILVA, J.C.; GIL FILHO, S.F. Da percepção e cognição à representação: reconstruções teóricas da geografia cultural e humanista. São Paulo: Terceira Margem; Curitiba: NEER, 2007.

COUTINHO, Maria da Penha de L; ARAÚJO, Ludgleydson Fernandes de; GONTIÈS, Bernard. Representações sociais do uso da maconha. Psicologia em Estudo, Maringá, v. 9, n. 3, p. 469477, set./dez. 2004.

FERNANDES, Tania Maria. Plantas Medicinais: memória da ciência no Brasil. Rio de Janeiro: Editora Fiocruz, 2004.

HERZLICH, Claudine. A problemática da representação social e sua utilidade no campo da doença. Physis: Revista Saúde Coletiva, Rio de Janeiro, 15(Suplemento): 57-70, 2005.

JODELET, Denise. (Org.) As representações sociais. Rio de Janeiro: EdUERJ, 2001.

JODELET, Denise. Número especial sobre as representações sociais. Psicol. Teor. Prat. vol.6, 2004, no.spe, p.7-9. Disponível em: $\leq$ http://pepsic.bvspsi.org.br/scielo.php?script $=$ S $1516-$ $\underline{36872004000300001 \& I n g=i s o>}$. ISSN 1516-3687. 
KOZEL, Salete. As representações no geográfico. In: MENDONÇA, F.; KOZEL, S. (Org.) Elementos de epistemologia da Geografia contemporânea. Curitiba, Ed. Da UFPR, 2002.

MOSCOVICI, Serge; DUVEEN, Gerard. Representações sociais: investigações em psicologia social. 2003.

RIGONATO, Valney Dias. O modo de vida das populações tradicionais e a interrelação com o cerrado da microrregião da Chapada dos Veadeiros:o distrito de Vila Borba. 2005. Dissertação (Mestrado em Geografia) - Instituto de Estudos SócioAmbientais, Universidade Federal de Goiás, Goiânia, 2005.

RIGONATO, V.D.;ALMEIDA, M.G. Cerrado: a fitofisionomia e a interrrelação com as populações tradicionais. Cerrados, Montes Claros, vol.1, n.1, p. $39-52$, jan./dez. 2004.

TOURINHO, M.J.G. Abordagem etnofarmacológica das plantas medicinais diuréticas no povoado de Capim Grosso, município de Canindé de São Francisco, Sergipe. Curituba, Aracaju, vol. 01, n.01, p. $34-71$,jan./dez.2000. 